\title{
Новые компоненты и решения от Würth Elektronik: всё меньше места для "магии" в электронике
}

Рассказывают генеральный директор группы компаний Würth Elektronik eiSos O. Конц и проект-менеджер по направлению электронные компоненты группы компаний Würth Elektronik eiSos А. В. Фадеева

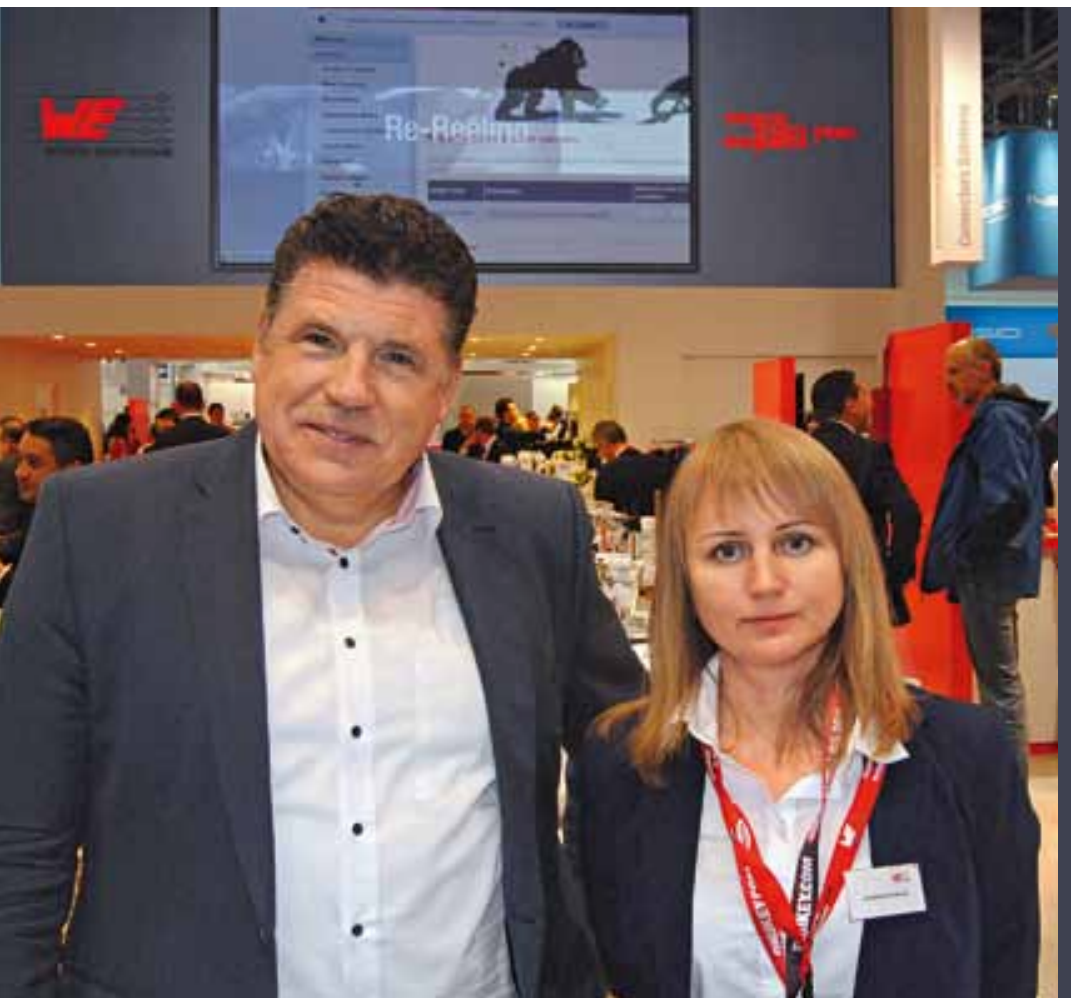

Группа компаний Würth Elektronik eiSos $\mathrm{GmbH} \&$ Co. KG (Würth Elektronik) - один из крупнейших в своем сегменте рынка производителей электронных и электромеханических компонентов и модулей. На 16 принадлежащих ей производственных площадках, расположенных в разных странах мира, работает около 8,3 тыс. сотрудников. Продукция группы компаний хорошо известна в отрасли, поэтому на выставке electronica 2018 мы попросили ее представителей рассказать о тех изделиях, которые они сами считают наиболее интересными и важными для себя на сегодняшний день. Со стендом Würth Elektronik нас знакомили ее генеральный директор Оливер Конц (Oliver Konz) и проектменеджер Анастасия Фадеева.

Стратегия развития Würth Elektronik направлена на максимальное расширение выпускаемой номенклатуры деталей, компонентов и функциональных узлов, устанавливаемых на печатную плату. Продвигаясь вперед в решении этой задачи, мы фактически каждый год организуем или приобретаем какое-нибудь новое направление бизнеса. И в этом году на выставке наш стенд состоит из 12 «островков", посвященных каждый своей тематике - фильтрации, питанию, соединителям, светодиодам и т.д., - и везде мы показываем немало новых изделий. Многие посетители стенда отмечают, что Würth Elektronik, по-видимому, представила наибольшее число новинок среди всех участников выставки

Самый большой интерес вызывают, пожалуй, конденсаторы. У нас появились три серии полимерных конденсаторов большой емкости - от 15 до 560 мкФ - в исполнении для поверхностного монтажа: WCAP-PHGP, WCAP-PHSE, WCAP-PHLE; мы видим перспективу широкого использования полимерных конденсаторов в будущем, поэтому развиваем эту линейку особенно интенсивно. Предлагаем также новую серию электролитических конденсаторов для поверхностного монтажа WCAP-ASLU. Это компактные изделия диаметром от 3 до 8 мм при емкости от 0,1 до 330 мкФ с низкими токами утечки, которые можно применять в качестве фильтров в DC/DC-преобразователях. Еще один новый продукт - суперконденсаторы серии WCAP-STSC ЕМКОСТЬю От 3 дО 50 Ф.

Много нового появилось в светодиодном подразделении: расширились линейки подсветочных, инфракрасных и ультрафиолетовых светодиодов, появились более миниатюрные решения по одно-, двух- и трехцветным светодиодам. Наконец, начал производиться совсем новый 
для нас класс продукции: фотодиоды и фототранзисторы в корпусах для поверхностного и выводного монтажа.

Еще одно новое направление нашего производства кварцевые генераторы (WE-SPHO) и резонаторы (WE-XTAL). Ихпроизводит недавно вошедшая в состав Würth Elektronik английская компания IQD Frequency Products. У них сильный инжиниринг, отлаженное производство, серьезная складская программа, и в целом компания отлично вписалась в нашу модель работы. Сейчас это подразделение находится в процессе интеграции: на новую продукцию должен быть выпущен весь принятый у нас комплект документации, в том числе 3D-модели и другие технические материалы для разработчика; изделия должны получить наши стандартные обозначения, нужно создать складские запасы, наконец, просто ввести в курс наших заказчиков. Этот процесс занимает от одного до двух лет, и лишь по его завершении продукт перестает позиционироваться как новый.

Многие заказчики спрашивали, когда в нашей номенклатуре появятся резисторы - и теперь они появились. Мы освоили производство нескольких серий токочувствительных резисторов для поверхностного монтажа типоразмеров от 0402 до 2512 (1225). Одна из серий, WRIS-KSKE, - тонкопленочные резисторы общего назначения (сопротивление от 0,05 до 10 Ом, мощность от 0,125 до 1 Вт), другая - толстопленочные резисторы WRIS-PSMB с небольшим диапазоном сопротивлений и мощностей (5-10 мОм, 0,33-1 Вт), но с повышенной стабильностью температурного коэффициента сопротивления (100 ppm/ $\left.{ }^{\circ} \mathrm{C}\right)$, третья - тонкопленочные резисторы WRIS-KWKB увеличенной мощности (до 2 Вт).

Мы сознательно начали с небольшой группы позиций. Изделие, которое Würth Elektronik анонсирует в статусе нового продукта, должно к этому моменту пройти все внутренние и внешние этапы тестирования, получить необходимые сертификаты и быть доступным со склада. Это большая работа, и в данном случае мы решили, что лучше начать с ограниченной номенклатуры, ознакомить с ней заказчиков, получить от них обратную связь и, в случае необходимости, что-то откорректировать в части параметров изделия, ценообразования и т. п. Если запустить сразу всю продуктовую линейку, сделать это будет значительно сложнее и дороже.

Большое внимание мы уделяем разработке и выводу на рынок готовых решений - функциональных модулей, которые, как детали конструктора LEGO, разработчик может быстро встроить в свою систему. Это относится в первую очередь к двум нашим самым сильным компетенциям - питанию и фильтрации, то есть к устройствам, функционирование которых основывается на использовании свойств ферромагнетиков. В обоих направлениях мы развиваем интегральные решения, акцентируя внимание на проблемах помехоподавления. Здесь унас также много новинок, самые ожидаемые из которых - готовые фильтры разного порядка для подключения ко входу и / или выходу устройства, которое нужно защитить от помех или которое само "шумит». В части модулей питания мы постоянно расширяем линейку DC/DC-преобразователей, предлагая заказчикам новые варианты. Среди них есть устройства со стандартным, массово востребованным набором характеристик, а есть и такие, аналогов которым на рынке не встречается.

На помехоподавлении хотелось бы остановиться подробнее. Этому направлению на нашем стенде посвящены два "островка". Электромагнитные помехи - сложное явление, разработчики электроники часто сравнивают их с черной магией: трудно понять, как они возникают, как именно действуют на устройство, справится оно с ними или нет. Свои наработки в этой области мы показываем на выставке под девизом No black magic any more. We are doctors, we know the recipe ("Больше никакой черной магии. Мы - доктора, мы знаем рецепт»). Соответственно, "островок" назван EMS Hospital Island - "ЭМС-больница". Основная идея состоит в том, чтобы показать разработчикам, что специалисты Würth Elektronik готовы помочь "вылечить" устройство от помех; представители компании, которые там работают, даже одеты в белые халаты - как врачи.

В Würth Elektronik работают высококвалифицированные эксперты в области фильтрации и импульсных источников питания. Мы выпустили уже 5-е издание книги «Трилогия магнетиков" (Trilogy of magnetics. Design Guide for EMI Filters Design, SMPS \& RF Citcuits), в котором добавлено

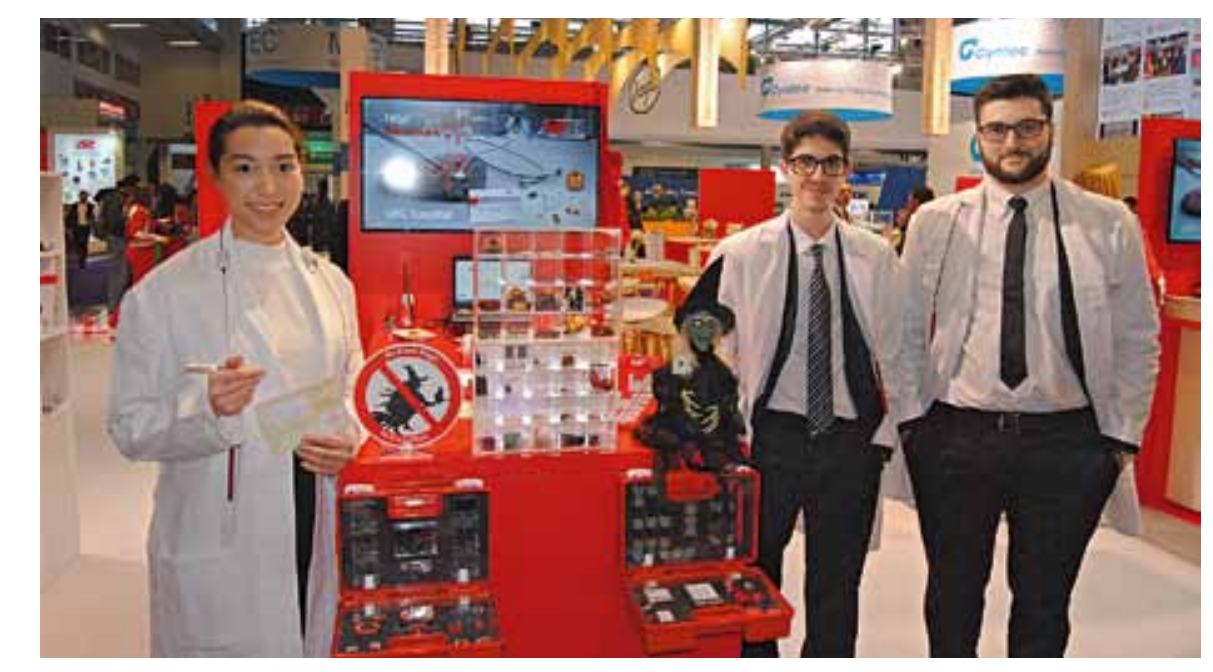

«ЭМС-больница» - «островок", посвященный помехоподавлению 

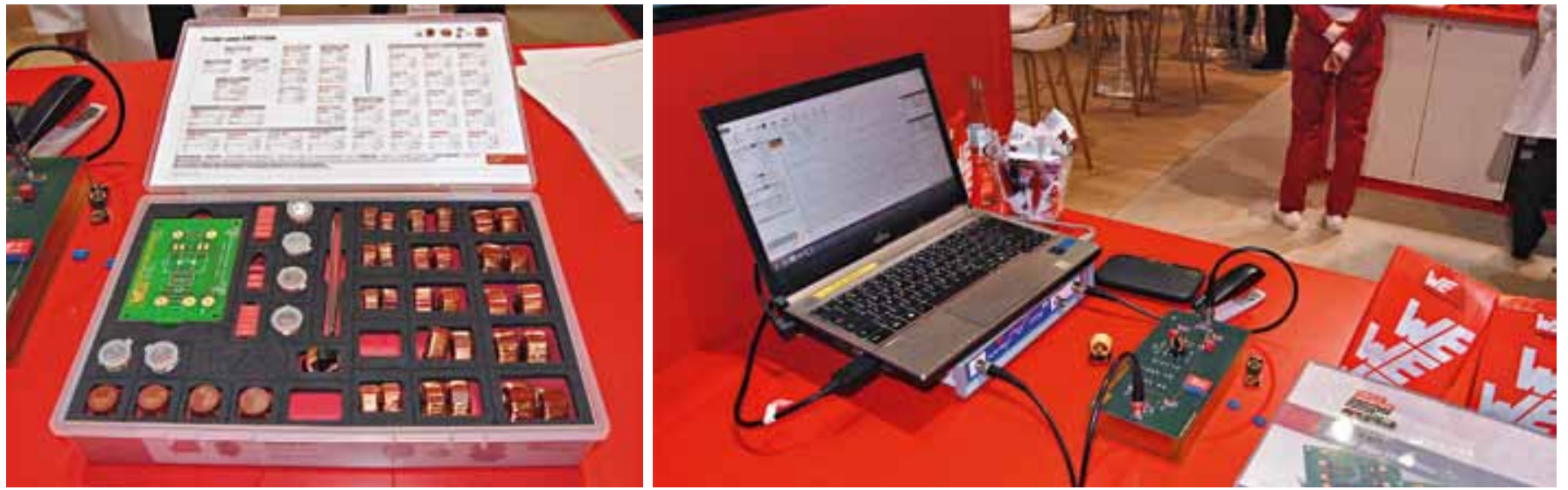

Дизайн-кит для разработки фильтров: слева - набор компонентов и макетных печатных плат (каталожный номер 744998); справа - испытательный стенд: собранная схема, подключенная к векторному анализатору цепей

порядка 100 страниц, содержащих практические примеры решений в области борьбы с помехами. И мы предлагаем не только готовые модули. У нас появились дизайн-киты, позволяющие заказчику правильно спроектировать свою систему: во-первых, исследовать электромагнитные поля, генерируемые его устройством, понять, какие возникают шумы, и, во-вторых, подобрать компоненты фильтрующих схем, способных эти шумы подавить - свести к приемлемому уровню.

Вообще, мы нацелены на то, чтобы к каждому типу продукции дать инструмент, который помогал бы понять, как этот продукт можно использовать наилучшим образом. Например, мы поставляем большую номенклатуру экранирующих материалов и предлагаем набор (каталожный номер 360002), с помощью которого разработчик может сам

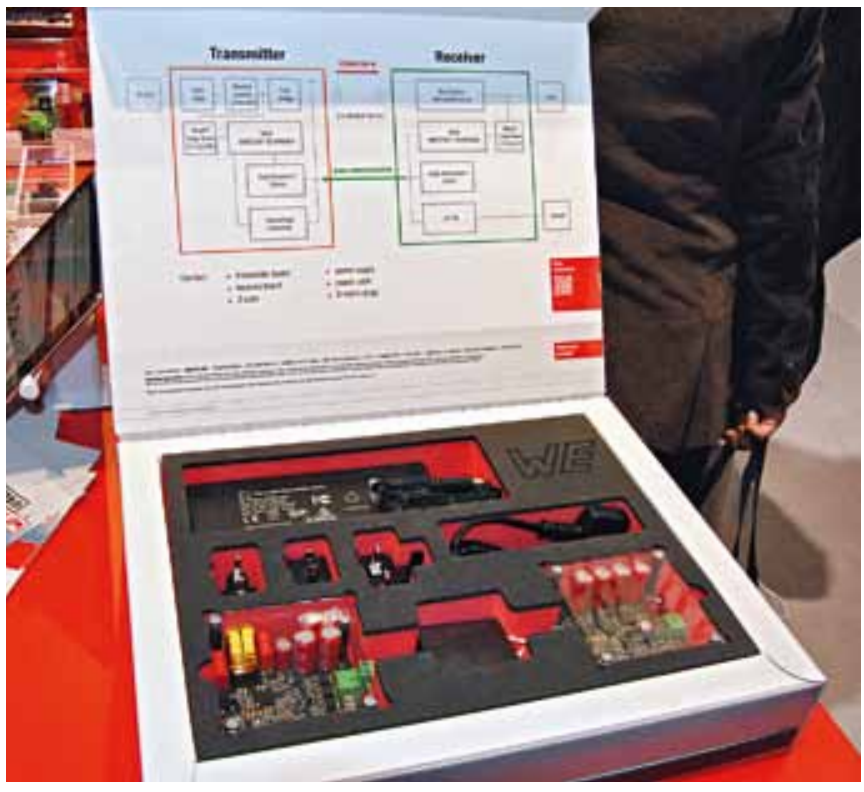

Дизайн-кит системы беспроводной зарядки (760308EMP) поэкспериментировать с материалом, подбирая оптимальную форму экрана для своей платы. Другой пример - дизайн-кит (номер 760308ЕМР) для отработки системы беспроводной зарядки мощностью до 200 Вт, позволяющий собрать небольшой стенд для подбора номиналов и исследования процессов в системе.

Если говорить о более масштабных вещах, то надо отметить, что глобальные изменения, происходящие в индустрии, благоприятны для Würth Elektronik. Преимущественной аудиторией еще при создании компании были определены малые и средние производства. Это и сегодня наш базовый сегмент, и мы видим тенденцию смещения рынка в его сторону. Да, крупные игроки продолжают играть свою роль; но автоматизация, универсализация оборудования, принципиально новые технологии формообразования и сборки, информационная интеграция процессов разработки, подготовки производства, изготовления изделий и их испытаний - всё то, что приносят в мир современные технологии, - расширяют возможности средних и совсем небольших компаний.

Эта тенденция в большой степени характерна и для России. Здесь мы ведем множество маленьких и средних проектов, которые очень нам интересны. Здесь хорошая образовательная база и умные, творческие люди. Европейцев, обученных действовать по тем или иным стандартам, российские инженеры иногда просто поражают своими идеями, выходящими за рамки привычных правил. При открытости рынка, доступности информации такие люди организуют небольшие, по 10-20 человек, проектные компании и запускают высококлассные проекты. Эта креативность, способность мыслить не по шаблону, найти необычное решение в сложной ситуации во многом определяет высокий потенциал российского рынка и страны в целом; а мы со своей стороны готовы оказывать таким компаниям всестороннюю поддержку.

Материал подготовлен В. Мейлицевым 


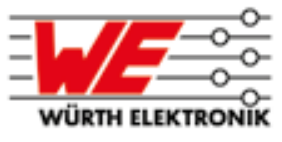

\section{WE DESIGN KITS}

\section{ОТБОРНЫЕ КОМПОНЕНТЫ В ПРОФЕССИОНАЛЬНЫХ НАБОРАХ ВСЕГДА ПОД РУКОЙ}

Индуктивности, конденсаторы, синфазные фильтры, ферриты, экранирующие материалы, электромеханические компоненты и многое другое в сформированных и упакованных по сериям и номиналам наборах-органайзерах .

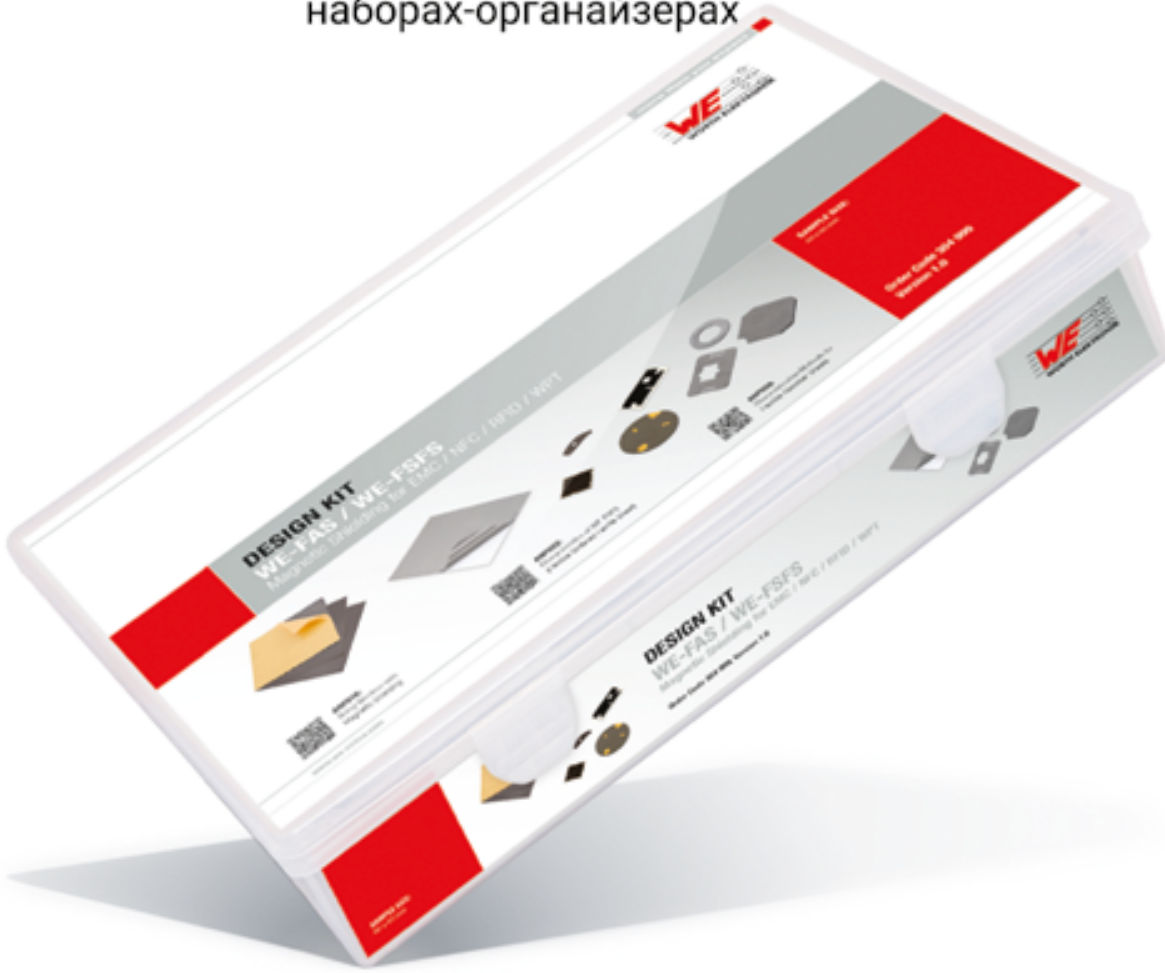

ГАРАНТИЯ ПОЖИЗНЕННОГО ПОПОЛНЕНИЯ

Закажите прямо сейчас: www.symmetron.ru/wekits

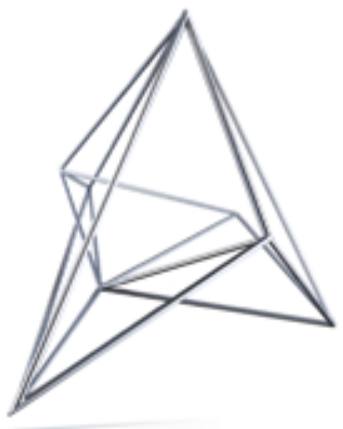

\section{Symmetron}

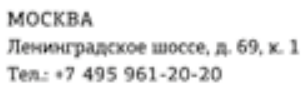

CAHKT-ПETEPEYP y. Талиинесая, a. 7 Ten: +7812 449-40-00 spbasymmetron.ru
Texeическая поддержка: wurth@symmetron.ru Группа компаний еСимметрове - эксклюзиваный Аистрибыютор компании Würth Elektronik в России. 